\title{
Fracture Resistance of Lithium Disilicate, Indirect Resin Composite and Zirconia By Using Dual Cure Resin Cements
}

\author{
Mohammed Badwan (D), Erkut Kahramanoglu (D) \\ Marmara University, Faculty of Dentistry, Department of Prosthodontics, Istanbul, Turkey.
}

Correspondence Author: Erkut Kahramanoglu

E-mail: erkut.kahramanoglu@marmara.edu.tr

Received: $18.09 .2020 \quad$ Accepted: 01.10 .2020

\begin{abstract}
Objective: The aim of the study was to examine the fracture resistance of lithium disilicate, indirect resin composite and zirconia by using dual cure resin cements.

Methods: Three groups of 180 samples $(n=60)$ of E-max, zirconia and indirect resin composite materials (10mm diameter and 1 mm thickness). Discs were fabricated and cemented with three dual curing resin cements. Aging treatment was then applied to the discs by using thermal cycle machine (at $5^{\circ} \mathrm{C}$ to $55^{\circ} \mathrm{C}$ /dwell time: 20s), 10000 cycles for 168 hours' 7 days. Fracture tests were performed to the sample discs using piston on three balls test to determine the biaxial flexure strength of the 180 discs of the three materials. The results were analysed by using one-way analysis of variance (ANOVA) and t-test.

Results: Statistically significant difference was found between control groups (before cementation and thermal cycle) and both group B (after cementation before thermal cycle) and group C (after cementation and thermal cycle) in all materials $(\mathrm{P}<0.05)$. Comparing Zirconia, Gradia and E-max all control groups showed statistically significant difference and Zirconia was showed greater flexural resistance against other materials. In addition, all materials also showed statistically significant difference in Variolink/Multilink cemented Group B and C. In Nexus cemented Group B and C statistically significant difference was found only Zirconia material. Similar to control group results, Zirconia material was showed greater flexural resistance values with both cements in Group B and C.

Conclusion: There is a difference between flexural strength of the three materials, Zirconia has a better flexural strength when compared to lithium disilicate and indirect resin composite.
\end{abstract}

Keywords: Zirconia, lithium disilicate, indirect resin composite, fracture resistance, thermal cycle

\section{INTRODUCTION}

Fracture resistance is the most essential factor for the survival of a dental restoration (1). The strength and aging of intraoral restorations are associated with the achievement of three parameters; strength, fit and esthetic $(1,2)$. An important characteristic of dental materials is fracture resistance as it depends on material resistance to crack from its internal defects (3). Such cracks may lead to microscopic fractures of the restoration margins and/ or the bulk fracture of the filling (4). According to Juntavee and Millstein (5) many ceramic materials have a critical strain fracture ranging from 0.05 to $0.2 \%$, thus to improve the strength of ceramics, the flexural modulus should be amended. Batchelor (6) found that strength and modulus of elasticity improves with the increase of the proportion of the crystalline phase after addition of the crystalline grains of high strength and elasticity. Moreover, latest arguments about dental ceramics stated that the presence of residual stresses influence the strength of dental ceramics (7). Ceramic materials are known for their good aesthetic, excellent fracture resistance, bonding durability and simplified fabrication techniques using CAD/ CAM, therefore, there is a growing interest in them (8). Lithium disilicate glass ceramic is one of the glass ceramic materials that has improved in performance in the last years; it is known for its high flexural strength and appealing translucency (9). In addition, Nawafleh (10) investigated the impact of core/veneer thickness ratio on the fracture strength of lithium disilicate crowns. According to this study results revealed that lithium disilicate had higher fracture resistance and more capable to survive. Additionally, Johansson et al (11) compared fracture resistance of monolithic zirconia and monolithic lithium disilicate (IPS E-max press) after thermal cycle and found zirconia has higher flexural strength (1000 $\mathrm{MPa}$ ) than lithium disilicate (400 MPa). Besides, Guazzato et al. found that among a type of materials; zirconia offers enhanced mechanical properties when compared to other ceramic materials. However, it has been demonstrated that 
flexural strength of zirconia decreases when subjected to such aging treatments and thermal cycle (12-15).

The most popular aesthetic restorative material used in prosthetic restorations are porcelain fused to metal (PFM); zirconia, lithium disilicate and indirect resin composite as they are thought to have excellent mechanical properties. Thus, they have been widely used by clinician because of their excellent aesthetic properties. Fracture resistance of lithium disilicate, Indirect resin composite and zirconia has been intensively studied. However, there is lack of research comparing the materials that which is better in terms of strength and colour maintenance. Thus, this study aimed to examine the fracture resistance of lithium disilicate (E-max), Indirect resin composite and zirconia by using dual cure resin cements. The null hypothesis was that there is no difference of flexural strength between the materials.

\section{METHODS}

\subsection{Preparing the samples}

Three groups of 180 samples $(n=60)(10 \mathrm{~mm}$ diameter, 1 $\mathrm{mm}$ thickness) (16-19) of E-max, zirconia and indirect resin composite materials (Table.1). The specimens were randomly divided into three experimental groups; Group A (control groups; before cementation and thermal cycle, before cementation after thermal cycle), Group B (after cementation before thermal cycle), Group C (after cementation and thermal cycle).

Table 1. Materials and groups

\begin{tabular}{|l|l|l|}
\hline Groups & Materials & Working methods \\
\hline $\begin{array}{l}\text { Group A: total ( } n=60) \\
\begin{array}{l}\text { Control group } \\
\text { (no cementation) }\end{array}\end{array}$ & $\begin{array}{l}\text { E-Max }(n=20) \\
\text { Zirconia }(n=20) \\
\text { Gradia }(n=20)\end{array}$ & $\begin{array}{l}\text { Control group no } \\
\text { thermal cycle+ fracture } \\
(n=30) \\
\text { Thermal cycle } \\
\text { Control group fracture } \\
(n=30)\end{array}$ \\
\hline $\begin{array}{l}\text { Group B: total ( } n=60) \\
\text { Divided into: } \\
\text { Variolink N + Multilink N auto- } \\
\text { mix ( } n=30) \\
\text { Nexus3 ( } n=30)\end{array}$ & $\begin{array}{l}\text { E-Max }(n=20) \\
\text { Gradia }(n=20)\end{array}$ & $\begin{array}{l}\text { Cementation + fracture } \\
+ \text { no thermal cycle. }\end{array}$ \\
\hline $\begin{array}{l}\text { Group C: total ( } n=60) \\
\text { Divided into: } \\
\text { Variolink N + Multilink auto- } \\
\text { mix ( } n=30) \\
\text { Nexus3 }(n=30)\end{array}$ & $\begin{array}{l}\text { E-Max }(n=20) \\
\text { Gradia }(n=20)\end{array}$ & $\begin{array}{l}\text { Cementation+ thermal } \\
\text { cycle + fracture. }\end{array}$ \\
\hline
\end{tabular}

For the E-max fabrication lost-wax and heat-pressed techniques (IPS E-max press Programat EP3000 press furnace, Ivoclar Vivadent, Schaan, Liechtenstein) was used for one shade of a lithium disilicate glass-ceramic material (IPS e-max Press HT and LT, A1 shade, n=60/each; Ivoclar Vivadent, Schaan, Liechtenstein). All samples were fabricated at $10 \mathrm{~mm}$ diameter and $1 \mathrm{~mm}$ thickness by using the CAD/ CAM Ceramill Motion2 (Amann Girrbach, Koblach, Austria) with 5-axis technology wet-grinding and dry-milling in one compact unit (figure 1). In order to achieve the accurate dimension of the wax block as shown in every sample takes 10 min milling. After that wax was removed from the CAD/ CAM machine and attached to a special sprue ring.

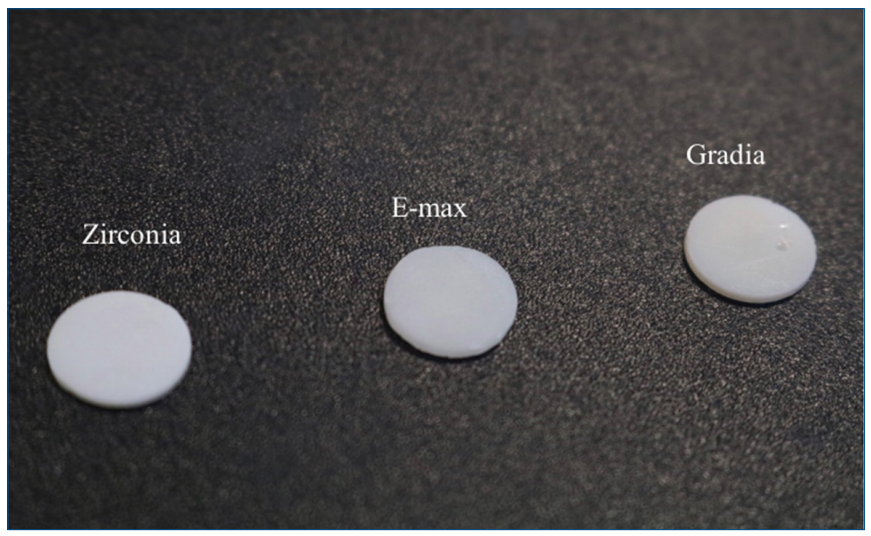

Figure 1. Final shape of the disc materials (Zirconia, E-max and Gradia)

Later on, investment powder 100g (Maruvest investment, Cerampress, Megadental, Germany) was poured and mixed with water using vacuum mixing unit (Renfert, Hilzingen, Germany) then placed inside $850^{\circ} \mathrm{C}$ furnace (burn-out furnace, Renfert Magma, Hilzingen, Germany) for 45 minutes. After furnace, it was ready for Programat EP3000 press furnace. After pressing the ring was separated using sandblasting unit (Renfert, Hilzingen, Germany) then removed the sprues using a diamond disc (Horico, Berlin, Germany). Then the disc was removed by using airborne particle abrasion unit (Toptec-Bego, Bremen, Germany) with $50-\mathrm{mm}$ glass beads at a pressure of 4 to 2 bars. The level of the pressure was decreased when it became closer to the ceramic material's surface. Both surfaces of the specimens were successively wet-ground to the desired dimensions with 220-, 320-, 500-, 600-, and 800-grade silicon carbide papers mounted on a surface grinder and polisher machine (MetaServ Grinder-Polisher; Buehler UK, Coventry, UK). The final step was to clean and wash the specimens under water. These are the steps of creating E-max samples to reach the accurate dimension required which is $10 \mathrm{~mm}$ diameter and $1 \mathrm{~mm}$ thick.

Zirkonzahn (Zirkonzahn, der Ahr, Gais, Italy) translucent blank was used for 60 fabricated samples of zirconia. The zirconia was manufactured in the CAD/CAM Ceramill Motion2 (Amann Girrbach, Koblach, Austria) with 5-axis technology wet-grinding and dry-milling in one compact unit by using CAD/CAM software and inserted the samples of $10 \mathrm{~mm}$ diameter and $1 \mathrm{~mm}$ thickness, after that the CAD/CAM milling machine started to mill the specimen for 10 minutes for each sample. After milling the specimen, a low speed hand piece (NSK ultimate $\mathrm{xl}$, Shimohinata, Japan) was used with a fine bur to remove the disc from the blank. After that, using a rubber finishing bur to soften the edges of the disc and scrubbed with a small brush. Then immersed the disc inside 
A1 water-based (Zirkonzahn, der Ahr, Gais, Italy) colour liquid to achieve the desired $A 1$ shade discs and placed them into the sand until dried. The zirconia specimens were sintered at $1500^{\circ} \mathrm{C}$ after they were made.

For indirect resin composite fabrication 60 samples of Gradia (GC Europe N.V: Leuven, Belgium) were manufactured into A1 shade by filling a metal ring of $10 \mathrm{~mm}$ diameter and $1 \mathrm{~mm}$ thick by using a tube of indirect resin composite Gradia manufactured from (GC Europe N.V, Leuven, Belgium). After filling the metal ring by the composite, the material was pressed between two glass slides and fixed with an elastic band, then was stapled with a stapler machine for 15 minutes to achieve the accurate dimension. After that it was inserted inside the light-cured machine (Lumamat100, Ivoclar Vivadent AG, Schaan, Liechtenstein) for 12 minutes to polymerise the discs.

\subsection{Cementation}

Before cementing the materials one surface of the disc was sandblasted by a suitable sandblasting unit with alumina sand from a distance of $10 \mathrm{~mm}$ for 15 seconds each (Renfert, Hilzingen, Germany, $30 \mu \mathrm{m}, 0.28 \mathrm{MP})$. These steps were applied with different types of pressure according to the bonds manufacture. The three materials were then cemented with Dual Cured Resin Cements: Variolink N Resin Cement System Base (shade " 0 " transparent), and catalyst " 0 " transparent shade (Ivoclar Vivadent AG, Schaan, Liechtenstein). Multilink N transparent shade (Ivoclar Vivadent AG, Schaan, Liechtenstein) and Nexus Third Generation NX 3 - Nexus3 "clear" shade (SDS Kerr, California, USA).

Cementation was prepared using Mylar strip technique" (20). The Mylar strip was placed over a glass slab and two adhesive tape strips (4M) were placed over the Mylar strip to act as spacer to ensure the standard thickness for all cements and prevent it from moving.

The Resin Cement Variolink N, Base and catalyst " 0 " transparent shade, respectively: was used for Gradia samples by first painting the samples with a special brush from the Variolink $\mathrm{N}$ kit with Monobond $\mathrm{N}$ and waited for one minute then mixed the (shade " 0 " transparent) base and catalyst together on a mixing paper pad with a spatula then applied on the disc by using a plastic instrument and placed on the glass slab. Additionally, the same procedure has been done for the E-max samples but first used hydrofluoric acid on each disc before applying the Monobond N. Multilink N transparent shade was used only for Zirconia by applying Monobond $\mathrm{N}$ with a special brush from the Multilink $\mathrm{N}$ kit. A dual-cured cement (base/catalyst) and a single-syringe with small tube on each disc were then placed on the glass slab.

Nexus Third Generation NX 3 - Nexus3 "Clear" shade was used for all materials (E-max, Zirconia and Gradia) by using a special brush from the kit to apply the Optibond XTR then waited for one minute before auto-mix. After that a dual-cured cement (single-syringe base/catalyst) was applied to the disc then placed on the glass slab.

All disk-shaped specimens were placed over the glass slab to create a Resin Cement layer with approximately $100 \pi \mathrm{m}$ thick underneath the ceramic disc (20). After that light cured device was applied for 1 minute for every sample of each material (Bluephase N; Ivoclar Vivadent AG, Schaan, Liechtenstein) to achieve optimum polymerization for each disc.

\subsection{Thermal cycle}

Thermocycling with temperature switching from $\left(5^{\circ} \mathrm{C}\right.$ to $55^{\circ} \mathrm{C} / \mathrm{dwell}$ time: $20 \mathrm{~s}$ (SD Mechatronik Thermocycler, Julabu, Germany) was performed; 10000 cycles for 168 hours (7 days) $(21,22)$. After thermocycling, the specimens were washed in water and dried in absorbent paper before fracture resistance test was made.

\subsection{Fracture resistance testing (Biaxial flexure test)}

All samples were individually mounted on a computer controlled universal testing machine (Shimadzu, Japan) with a loadcell of $5 \mathrm{kN}$ and data was recorded using computer software (Shimadzu Software). The test was done by compressive mode of load using a metallic rod with a flat end tip (1.4mm radius) as recommended in ISO 6872. This metallic rod is attached to the upper movable compartment of testing machine traveling at cross - head speed of $1 \mathrm{~mm} /$ min. The lower immobile base was fixed with screws. The piston on three balls test was used to determine the biaxial flexure strength of the 180 discs (10mm diameter $1 \mathrm{~mm}$ thick) of the three materials. The disc specimens were supported on three steel balls ( $2.38 \mathrm{~mm}$ diameter) positioned 120 distances between each other on a circle (7.44-mm radius). The force was applied to the middle of the specimen. The recorded fracture load in $(\mathrm{N})$ was then inserted into the following equation to give the flexural strength value in (MPa):

$$
S=-0.2387 P(X-Y) / d^{2}
$$

$\mathrm{S}$ is the flexure strength in ( $\mathrm{MPa}), \mathrm{P}$ is the total load-causing fracture in $(\mathrm{N})$, and $d$ is the specimen thickness at the fracture origin. $X$ and $Y$ were determined as follows

$$
\begin{aligned}
& X=(1+v) \ln \left(r_{2} / r_{3}\right)^{2}+[(1-v) / 2]\left(r_{2} / r_{3}\right)^{2} \\
& Y=(1+v)\left[1+\ln \left(r_{1} / r_{3}\right)^{2}\right]+(1-v)\left(r_{1} / r_{3}\right)^{2}
\end{aligned}
$$

The equation translated in as $r_{1}$ is the radius of the support Circle in $(\mathrm{mm}), r_{2}$ is the radius of the loaded area or the tip of the piston in $(\mathrm{mm})$, and $r_{3}$ is the radius of the specimen in $(\mathrm{mm})$ and $(\mathrm{v})$ is Poisson's ratio and it is noticed to be changed from material to another (figure 2). According to lithium disilicate Poisson's ratio is (0.23) (23), (0.342) for Zirconia according to material market instructions and for Gradia we assumed (0.31) (24). 


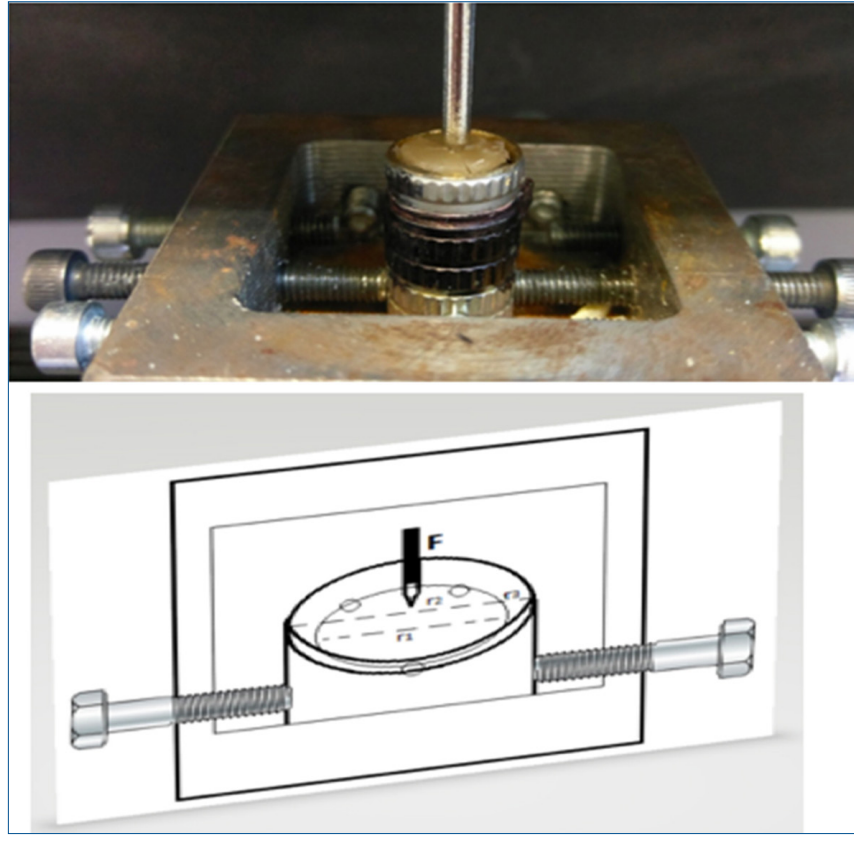

Figure 2. Fracture resistance test

\subsection{Statistical analysis}

Descriptive statistics and inferential statistic techniques were used for data analysis using SPSS (SPSS 23,00, SPSS Inc., Chicago, IL, USA). Statistical significance difference between the variables was analysed using t-test and analysis of variance and One-way ANOVA (post hoc) followed by Tukey at significance level of $P<0.05$.

\section{RESULTS}

Table.2 illustrates the descriptive statistics of the flexural strength results of the three materials E-max, Zirconia and Gradia. One-way ANOVA (post hoc test) was used to examine the difference of flexural strength between materials according to the cements used and the difference between groups $(A, B$, and $C)$. For instance, the difference between E-max Variolink control group A and E-max Variolink group $B$, and the difference between Variolink group $B$ and Variolink group $C$ etc (Table 3 ). The study results showed a statistical significant difference between the groups and material used in most of the variables. For instance, there was a significant difference between E-max control group (before cementation and thermal cycle) and Variolink Group B (after cementation before thermal cycle) $(P=0.000)$ and also a difference between control group and Variolink Group C (after thermal cycle) $(P=0.020)$. One-way ANOVA was also used to examine the difference between flexural strength of the three materials among all the groups. According to the study results presented in Table.4 there is statistical significance difference between the majority of the variables. Independent sample t-test determined the effect of thermal cycle on the flexural strength of each material. The results indicated no significant difference between control group $A$ before thermal cycle and control group $A$ after thermal cycle in all materials ( $E-\max P=1.000)$, (Zirconia $\mathrm{P}=0.076$ ) and (Gradia $\mathrm{P}=0.917$ ).

Table 2. Flexural strength results of the three materials E-max, Zirconia and Gradia

\begin{tabular}{|c|c|c|c|c|c|c|c|c|c|c|c|c|c|c|c|c|c|c|}
\hline \multirow[b]{3}{*}{$S$} & \multicolumn{6}{|c|}{$\begin{array}{l}E-\max \\
(n=60)\end{array}$} & \multicolumn{6}{|c|}{$\begin{array}{c}\begin{array}{c}\text { Zirconia } \\
(n=60)\end{array}\end{array}$} & \multicolumn{6}{|c|}{$\begin{array}{l}\text { Gradia } \\
(n=60)\end{array}$} \\
\hline & \multicolumn{2}{|c|}{$\begin{array}{l}\text { A Group } \\
(n=20)\end{array}$} & \multicolumn{2}{|c|}{$\begin{array}{l}\text { B Group } \\
(n=20)\end{array}$} & \multicolumn{2}{|c|}{$\begin{array}{l}\text { C Group } \\
(n=20)\end{array}$} & \multicolumn{2}{|c|}{$\begin{array}{c}\text { A Group } \\
(n=20)\end{array}$} & \multicolumn{2}{|c|}{$\begin{array}{c}\text { B Group } \\
(n=20)\end{array}$} & \multicolumn{2}{|c|}{$\begin{array}{l}\text { C Group } \\
(n=20)\end{array}$} & \multicolumn{2}{|c|}{$\begin{array}{c}\text { A Group } \\
(n=20)\end{array}$} & \multicolumn{2}{|c|}{$\begin{array}{c}\text { B Group } \\
(n=20)\end{array}$} & \multicolumn{2}{|c|}{$\begin{array}{c}\text { C Group } \\
(n=20)\end{array}$} \\
\hline & C & CT & v & $N$ & v & $N$ & C & CT & $M$ & $\mathbf{N}$ & $M$ & $N$ & C & CT & v & $\mathbf{N}$ & v & $\mathbf{N}$ \\
\hline S1 & 163.8 & 163.5 & 513.5 & 212 & 197.2 & 284 & 582.5 & 607.3 & 864.4 & 1094.4 & 741.3 & 904.3 & 110 & 86.6 & 457.7 & 407.3 & 273 & 389 \\
\hline S2 & 172.9 & 155.9 & 642.9 & 185 & 448 & 240.8 & 659.5 & 753.4 & 1007.7 & 1007.6 & 753.9 & 958.8 & 95.9 & 81 & 261 & 435.3 & 143.6 & 367.8 \\
\hline S3 & 152.5 & 185.2 & 367.6 & 335.6 & 157.3 & 193.3 & 713.9 & 718.3 & 943.7 & 947.8 & 917.8 & 890.2 & 87 & 65.8 & 297.3 & 223.9 & 132.7 & 149 \\
\hline S4 & 169.4 & 204.4 & 446.5 & 348.4 & 232.7 & 183.8 & 703.9 & 667.2 & 896.2 & 935.4 & 879.2 & 600.2 & 117.4 & 72.4 & 297.6 & 296.2 & 154.8 & 172.1 \\
\hline S5 & 150.6 & 120.4 & 346.2 & 294.8 & 140.4 & 284.8 & 735.4 & 558.2 & 1014.8 & 1028.4 & 899.4 & 984.6 & 108.7 & 107.7 & 244.3 & 314.6 & 262.2 & 248.9 \\
\hline S6 & 200.0 & 134.6 & 457.6 & 209.7 & 216.2 & 141.5 & 816.9 & 614.3 & 1009.6 & 942.9 & 863.5 & 859 & 94.3 & 81.2 & 199.6 & 306.4 & 187.6 & 159.2 \\
\hline S7 & 155.4 & 140.6 & 582.6 & 222.3 & 366 & 141.9 & 660.3 & 715.3 & 854 & 855.5 & 745.5 & 910.3 & 105.3 & 63.7 & 161.6 & 159.8 & 98.7 & 138.2 \\
\hline S8 & 166.2 & 130.3 & 519.7 & 555.1 & 226.4 & 310.9 & 680.8 & 482.9 & 941.6 & 1050.5 & 996.3 & 1002.7 & 100.5 & 88.5 & 108.9 & 399 & 129.3 & 107.8 \\
\hline S9 & 179.7 & 168.9 & 358 & 399.5 & 226.9 & 221.8 & 708.9 & 407.4 & 1075.9 & 882.2 & 970.6 & 1013.1 & 87 & 74.4 & 244.1 & 407.3 & 132.7 & 319.1 \\
\hline S10 & 173.1 & 178.5 & 566.9 & 260.1 & 477.3 & 395 & 738.1 & 537.6 & 757.7 & 1014 & 849.5 & 535.4 & 88.6 & 76.4 & 203.9 & 199.5 & 240.8 & 264.7 \\
\hline Mean & 168.4 & 158.2 & 480.2 & 302.3 & 268.8 & 239.8 & 700 & 606.2 & 936.6 & 975.9 & 861.7 & 865.9 & 99.5 & 79.8 & 247.6 & 314.9 & 175.5 & 231.6 \\
\hline
\end{tabular}

S: Sample; C: Control group before thermal cycle; CT: Control after thermal cycle; V: Variolink cement; N: Nexus cement 
Table 3. The difference of flexural strength between materials according to the cements

\begin{tabular}{|c|c|c|c|c|c|c|}
\hline \multirow{2}{*}{ Material } & & & \multirow{2}{*}{ Difference of mean } & \multirow{2}{*}{ P value } & \multicolumn{2}{|c|}{ 95\% Confidence Interval } \\
\hline & & & & & Lower limit & Upper limit \\
\hline \multirow{12}{*}{ E-max } & \multirow{2}{*}{ Control } & Variolink Group B & $-311.79000^{*}$ & .000 & -395.1812 & -228.3988 \\
\hline & & Variolink Group C & $-100.48000^{*}$ & .020 & -183.8712 & -17.0888 \\
\hline & \multirow{2}{*}{ Variolink Group B } & Control & $311.79000^{*}$ & .000 & 228.3988 & 395.1812 \\
\hline & & Variolink Group C & 211.31000* & .000 & 127.9188 & 294.7012 \\
\hline & \multirow{2}{*}{ Control } & Nexus Group B & $-133.89000^{*}$ & .001 & -207.8151 & -59.9649 \\
\hline & & Nexus Group C & -71.42000 & .058 & -145.3451 & 2.5051 \\
\hline & \multirow{2}{*}{ Nexus Group B } & Control & $133.89000^{*}$ & .001 & 59.9649 & 207.8151 \\
\hline & & Nexus Group C & 62.47000 & .094 & -11.4551 & 136.3951 \\
\hline & \multirow{2}{*}{ Control after thermal cycle (CAT) } & Variolink Group B & $-321.92000^{*}$ & .000 & -406.1601 & -237.6799 \\
\hline & & Variolink Group C & $-110.61000^{*}$ & .012 & -194.8501 & -26.3699 \\
\hline & \multirow{2}{*}{ Control after thermal cycle (CAT) } & Nexus Group B & $-144.02000^{*}$ & .001 & -218.9014 & -69.1386 \\
\hline & & Nexus Group C & $-81.55000^{*}$ & .034 & -156.4314 & -6.6686 \\
\hline \multirow{12}{*}{ Zirconia } & \multirow{2}{*}{ Control } & Multilink Group B & $-236.54000^{*}$ & .000 & -313.5809 & -159.4991 \\
\hline & & Multilink Group C & $-161.68000^{*}$ & .000 & -238.7209 & -84.6391 \\
\hline & \multirow{2}{*}{ Multilink Group B } & Control & $236.54000^{*}$ & .000 & 159.4991 & 313.5809 \\
\hline & & Multilink Group C & 74.86000 & .056 & -2.1809 & 151.9009 \\
\hline & \multirow{2}{*}{ Control } & Nexus Group B & $-275.85000^{*}$ & .000 & -377.7059 & -173.9941 \\
\hline & & Nexus Group C & $-165.84000^{*}$ & .002 & -267.6959 & -63.9841 \\
\hline & \multirow{2}{*}{ Nexus Group B } & Control & $275.85000^{*}$ & .000 & 173.9941 & 377.7059 \\
\hline & & Nexus Group C & $110.01000^{*}$ & .035 & 8.1541 & 211.8659 \\
\hline & \multirow{2}{*}{ Control after thermal cycle (CAT) } & Multilink Group B & $-330.37000^{*}$ & .000 & -421.7789 & -238.9611 \\
\hline & & Multilink Group C & $-255.51000^{*}$ & .000 & -346.9189 & -164.1011 \\
\hline & \multirow{2}{*}{ Control after thermal cycle (CAT) } & Nexus Group B & $-369.68000^{*}$ & .000 & -482.7945 & -256.5655 \\
\hline & & Nexus Group C & $-259.67000^{*}$ & .000 & -372.7845 & -146.5555 \\
\hline \multirow{12}{*}{ Gradia } & \multirow{2}{*}{ Control } & Variolink Group B & $-148.13000^{*}$ & .000 & -208.2132 & -88.0468 \\
\hline & & Variolink Group C & $-76.07000^{*}$ & .015 & -136.1532 & -15.9868 \\
\hline & \multirow{2}{*}{ Variolink Group B } & Control & $148.13000^{*}$ & .000 & 88.0468 & 208.2132 \\
\hline & & Variolink Group C & $72.06000^{*}$ & .021 & 11.9768 & 132.1432 \\
\hline & \multirow{2}{*}{ Control } & Nexus Group B & $-215.46000^{*}$ & .000 & -289.9173 & -141.0027 \\
\hline & & Nexus Group C & $-132.11000^{*}$ & .001 & -206.5673 & -57.6527 \\
\hline & \multirow{2}{*}{ Nexus Group B } & Control & $215.46000^{*}$ & .000 & 141.0027 & 289.9173 \\
\hline & & Nexus Group C & $83.35000^{*}$ & .030 & 8.8927 & 157.8073 \\
\hline & \multirow{2}{*}{ Control after thermal cycle (CAT) } & Variolink Group B & $-167.83000^{*}$ & .000 & -228.0255 & -107.6345 \\
\hline & & Variolink Group C & $-95.77000^{*}$ & .003 & -155.9655 & -35.5745 \\
\hline & \multirow{2}{*}{ Control after thermal cycle (CAT) } & Nexus Group B & $-235.16000^{*}$ & .000 & -309.7080 & -160.6120 \\
\hline & & Nexus Group C & $-151.81000^{*}$ & .000 & -226.3580 & -77.2620 \\
\hline
\end{tabular}

Table 4. The difference between flexural strength of the three materials among all groups

\begin{tabular}{|c|c|c|c|c|c|c|}
\hline & & & \multirow{2}{*}{ Difference of mean } & \multirow{2}{*}{$P$ value } & \multicolumn{2}{|c|}{ 95\% Confidence Interval } \\
\hline & & & & & Lowe limit & Upper limit \\
\hline \multirow{4}{*}{$\begin{array}{l}\text { Control group } \\
\text { Group A }\end{array}$} & \multirow{2}{*}{ E-max } & Zirconia & $-531.66000^{*}$ & .000 & -565.6306 & -497.6894 \\
\hline & & Gradia & $68.89000^{*}$ & .000 & 34.9194 & 102.8606 \\
\hline & \multirow{2}{*}{ Zirconia } & E-max & $531.66000^{*}$ & .000 & 497.6894 & 565.6306 \\
\hline & & Gradia & $600.55000^{*}$ & .000 & 566.5794 & 634.5206 \\
\hline \multirow{4}{*}{$\begin{array}{l}\text { Control group after } \\
\text { thermal Group A }\end{array}$} & \multirow[b]{2}{*}{ E-max } & Zirconia & $-447.96000^{*}$ & .000 & -509.0345 & -386.8855 \\
\hline & & Gradia & $78.46000^{*}$ & .014 & 17.3855 & 139.5345 \\
\hline & \multirow{2}{*}{ Zirconia } & E-max & $447.96000^{*}$ & .000 & 386.8855 & 509.0345 \\
\hline & & Gradia & $526.42000^{*}$ & .000 & 465.3455 & 587.4945 \\
\hline \multirow{4}{*}{$\begin{array}{l}\text { Variolink/ } \\
\text { Multilink } \\
\text { Group B }\end{array}$} & \multirow{2}{*}{ E-max } & Zirconia & -456.4100 & .000 & -564.41610 & -348.403898 \\
\hline & & Gradia & 232.55000 & .000 & 124.543898 & 340.556102 \\
\hline & \multirow{2}{*}{ Zirconia } & E-max & 456.41000 & .000 & 348.403898 & 564.416102 \\
\hline & & Gradia & 688.96000 & .000 & 580.953898 & 796.966102 \\
\hline \multirow{4}{*}{$\begin{array}{l}\text { Variolink/ } \\
\text { Multilink } \\
\text { Group C }\end{array}$} & \multirow{2}{*}{ E-max } & Zirconia & -592.8600 & .000 & -696.50465 & -489.215343 \\
\hline & & Gradia & 93.30000 & .084 & -10.344657 & 196.944657 \\
\hline & \multirow{2}{*}{ Zirconia } & E-max & 592.860000 & .000 & 489.215343 & 696.504657 \\
\hline & & Gradia & 686.160000 & .000 & 582.515343 & 789.804657 \\
\hline \multirow{4}{*}{$\begin{array}{l}\text { Nexus } \\
\text { Group B }\end{array}$} & \multirow{2}{*}{ E-max } & Zirconia & -673.6200 & .000 & -780.66878 & -566.571217 \\
\hline & & Gradia & -12.68000 & .954 & -119.72878 & 94.368783 \\
\hline & \multirow{2}{*}{ Zirconia } & E-max & 673.62000 & .000 & 566.571217 & 780.668783 \\
\hline & & Gradia & 660.94000 & .000 & 553.891217 & 767.988783 \\
\hline \multirow{4}{*}{$\begin{array}{l}\text { Nexus } \\
\text { Group C }\end{array}$} & \multirow{2}{*}{ E-max } & Zirconia & -626.0800 & .000 & -760.54135 & -491.618650 \\
\hline & & Gradia & 8.20000 & .987 & -126.26135 & 142.661350 \\
\hline & \multirow{2}{*}{ Zirconia } & E-max & 626.08000 & .000 & 491.618650 & 760.541350 \\
\hline & & Gradia & 634.28000 & .000 & 499.818650 & 768.741350 \\
\hline
\end{tabular}




\section{DISCUSSION}

This study includes an examination of three esthetic materials, which are considered the most popular esthetic materials used in the field of dentistry. The materials include Lithium disilicate, Indirect Resin Composite and Zirconia. Aging process was applied on the materials using thermal cycle machine $(10,000$ cycles), this is equivalent to one year of clinical service of composite (25). The current study determined the difference of flexural strength between the materials (Zirconia, E-max and Gradia). According to the results shown in Table 3 there was a statistically significance difference between all the variables. However, there was no significant difference between E-max Nexus group B (after cementation, before thermal cycle) and E-max Nexus group $C$ (cementation with thermal cycle) $(P=0.094)$. The reason for this could be that the Nexus cement was better at maintaining the strength of the material even after thermal cycling. According to Lambade et al (26) Nexus NX3 had the highest value of shear bond strength and Variolink II had the lowest. Moreover, the results showed a significant difference between E-max control group (before cementation and thermal cycle) and Variolink Group B (after cementation, before thermal cycle), a difference between control group and Variolink Group C (after thermal cycle) and the difference between Groups $B$ and $C(P<0.050)$ mean difference (-311.79000; - 100.48000; 211.31000*). Group B (after cementation before thermal cycle) showed the highest mean values when compared to group $A$ and $C$. However, this study determined the effect of thermal cycle on the flexural strength of each material. According to the study results, there was no statistically significant difference between control group A before thermal cycle and control group $A$ after thermal cycle in all materials $(P<0.05)$. Porto et al (27) evaluated the effect of thermal cycling process on four ceramic materials and unlike the current study they found that thermal cycle had a significant impact on the toughness of all materials. In addition, according to Shafter et al (28) also found that thermocycling has an impact on the flexural strength of different materials, however, their study found no significant difference between the impact of thermal cycle and water soaking. Moresi et al (29) similarly found that flexural strength significantly decreased after thermal cycling protocols in all composites materials tested. In the current study it was also demonstrated that in most samples there is a difference between control and cemented discs (groups B and C) (Table 3). This indicates that factors such as the material, type of cement and heat exposure all have an impact on the aging and the flexural strength of teeth. Li et al (30) compared the differences in flexural strength and compressive strength between different resin-modified luting glass cements that are commonly used in clinics. According to their study, all cements had an impact on the flexural strength on the ceramic, chemical cure cements had a superior flexural strength. Moreover, Fracncescantonio et al (31) evaluated the effects of curing mode and viscosity on the biaxial flexural strength (FS) and modulus (FM) of dual resin cements. Their study found that the use of different cements with different viscosities has an impact on the biomechanical behaviour of luting materials. Besides, insignificance difference between the groups that was revealed in current study was more apparent in group $B$. This again indicates that not exposing the teeth to heat will lengthen its age. Prakki et al (32) found that the non-cemented groups had a lower fracture loads compared to the cemented groups. On the other hand, Scherrer et al (33) found that treating ceramics with resin cements smoothed its sharpness and roughness which makes it more prone to fracture.

In addition, the current study results also detected a significant difference between the materials in nearly all variable in groups A, B and C (Table 4). Therefore, the null hypothesis has been rejected. It was clearly shown in the results presented in Table 4 that Zirconia has a better flexural strength in all the groups followed by E-max and then Gradia. Jihad et al (34) similarly found that Zirconia materials showed superior biaxial flexural strength values than the lithium disilicate glass ceramics. According to Piconi and Maccauro (35) Zirconia is strongly dependent on its grain size, thus, it cannot be easily transformed. Johansson et al (36) also found higher strength for the zirconia crowns compared to lithium disilicate crowns when undergone the thermal cycle machine. In relation to Gradia, there is lack of studies on the flexural strength difference between Gradia (indirect composite) and Zirconia. Most studies assessed the difference between indirect and direct composite. For instance, Borba et al (37) evaluated the flexural strength and hardness of direct and indirect composites. According to their study results direct composite showed higher mean value than the indirect composites. Similarly, Cesar et al (38) found that the flexural strength of direct composite (Z100) was much higher than indirect composite materials (Artglass, Belleglass, Sculpture and Targis). Nevertheless, the current study found insignificance difference was between E-max and Gradia (Variolink group C), E-max and Zirconia (Nexus group $B$ ) and E-max and Gradia (Nexus group C) with ( $P>0.05$ ). This may be due that fact that Nexus NX3 has a higher value of shear bond strength than Variolink as mentioned earlier (25). Thus, the Nexus balanced between E-max and Gradia, whilst Zirconia remained with the highest strength.

\section{CONCLUSION}

Within the limitations of this study the following conclusions may be drawn:

i) There is a difference between flexural strength of the three materials, Zirconia has a better flexural strength when compared to E-max and Gradia.

ii) Different types of cement could have an impact on the flexural strength of ceramic materials.

\section{REFERENCES}

[1] Singh K, Suvarna S, Agnihotri Y, Sahoo S, Kumar P. Color stability of aesthetic restorative materials after exposure to commonly 
consumed beverages: A systematic review of literature. Eur J Prostho 2015; 2: 15-22.

[2] de Oliveira, $M$ and Botta A. Effects of immersion media and repolishing on color stability and superficial morphology of nanofilled composite resin. Microsc Microanal 2014; 20: 12341239.

[3] Bonilla Bonilla ED, Mardirossian G, Caputo AA. Fracture toughness of posterior resin composites. Quintessence Int 2001; 32: 206-210.

[4] de Freitas CR, Miranda MI, de Andrade MF, Flores VH, Vaz LG, Guimarães C. Resistance to maxillary premolar fractures after restoration of class II preparations with resin composite or ceromer. Quintessence Int 2002; 33: 589-594.

[5] Juntavee, $\mathrm{N}$ and Millstein, P. Effect of surface roughness and cement space on crown retention. Journal of Prosthet Dent 1992; 63: 482-486.

[6] Batchelor RF. Transverse Test for Non-metallic Denture Base Materials: A Modified and Improved Method, Br Dent J 1969; 26: 30-31.

[7] O'Brien WJ, Johnston WM, Fanian F, Lambert S. The surface roughness and gloss composites. J Dent Res 1984; 685-688.

[8] Hooshmand T, Parvizi S, Keshvad A. Effect of surface acid etching on the biaxial exural strength of two hot - pressed glass ceramics. J Prosthodont 2008; 17: 415-419.

[9] Topcu FT, Sahinkesen G, Yamanel K, Erdemir U, Oktay EA, Ersahan S. Influence of different drinks on the colour stability of dental resin composites. Eur J Dent 2009; 3: 50-56.

[10] Nawafleh N, Mack F, Öchsner A. Masticatory loading and oral environment simulation in testing lithium disilicate restorations: A structured review. In Applications of Computational Tools in Biosciences and Medical Engineering. Springer International Publishing 2015; 189-215.

[11] Johansson C, Kmet G, Rivera J, Larsson C, Vult Von Steyern P. Fracture strength of monolithic all-ceramic crowns made of high translucent yttrium oxide stabilized zirconium dioxide compared to porcelain veneered crowns and lithium disilicate crowns. Acta Odontol Scand 2014; 72: 145-153.

[12] Cotes C, Arata A, Melo RM, Bottino MA, Machado JP, Souza RO. Effects of aging procedures on the topographic surface, structural stability, and mechanical strength of a ZrObased dental ceramic. Dent Mater 2014; 30: 396-404.

[13] Flinn B, deGroot D, Mancl L, Raigrodski AJ. Accelerated aging characteristics of three yttria-stabilized tetragonal zirconia polycrystalline dental materials. J Prosthet Dent 2012; 108 : 223-230.

[14] Kohorst P, Dittmer MP, Borchers L, Stiesch-Scholz M. Influence of cyclic fatigue in water on the load-bearing capacity of dental bridges made of zirconia. Acta Biomater 2008; 4: 1440-1447.

[15] Guazzato M, Albakry M, Ringer SP, Swain MV. Strength, fracture toughness and microstructure of a selection of all ceramic materials. Part II. Zirconia - based dental ceramics. Dent Mater 2004; 20: 449-456.

[16] Almansour, $\mathrm{H}$ and Alqahtani, F. The Effect of in vitro Aging and Fatigue on the Flexural Strength of Monolithic Hightranslucency Zirconia Restorations. J Contemp Dent Pract 2018; 19: 867-873.

[17] Ozer F, Naden A, Turp V, Mante F, Sen D, Blatz MB. Effect of thickness and surface modifications on flexural strength of monolithic zirconia. J Prosthet Dent 2018; 119: 987-993.

[18] Bagheri H, Hooshmand T, Aghajani F. Effect of Ceramic Surface Treatments After Machine Grinding on the Biaxial Flexural
Strength of Different CAD/CAM Dental Ceramics. J Dent (Tehran) 2015; 12: 621-629.

[19] Muench A, Correa IC, Grande RH, João M. The effect of specimen dimensions on the flexural strength of a composite resin. J Appl Oral Sci 2005; 13: 265-268.

[20] Hernandes DK, Arrais CA, Lima Ed, Cesar PF, Rodrigues JA. Influence of resin cement shade on the color and translucency of ceramic veneers. J Appl Oral Sci 2016; 24: 391-396.

[21] Ghavami-Lahiji M, Firouzmanesh M, Bagheri $H$, Jafarzadeh Kashi TS, Razazpour F, Behroozibakhsh M. The effect of thermocycling on the degree of conversion and mechanical properties of a microhybrid dental resin composite. Restor Dent Endod 2018; 43: e26.

[22] Al-Shalawi, H, Al-Saif, M, Mohammad, N, hagha, R, Alhaj, M, Al Saffan, A. Effect of Discolored Drinks Available in the Saudi Market on Composite Restorations. IOSR Journal of Dental and Medical Sciences. 2017; 16: 114-119.

[23] Albakrya, M, Guazzatoa, M, Swain, M. Fracture toughness and hardness evaluation of three pressable all-ceramic dental materials. J Dent 2003; 31: 181-188.

[24] Chung SM, Yap AU, Koh WK, Tsai KT, Lim CT. Measurement of Poisson's ratio of dental composite restorative materials. Biomaterials. 2004; 25: 2455-2460.

[25] Gale MS, Darvell BW. Thermal cycling procedures for laboratory testing of dental restorations. J Dent 1999; 27: 89-99.

[26] Lambade DP, Gundawar SM, Radke UM. Evaluation of adhesive bonding of lithium disilicate ceramic material with duel cured resin luting agents. J Clin Diagn Res 2015; 9: ZC01-ZC5.

[27] Porto TS, Roperto RC, Akkus A, Akkus O, Teich S, Faddoul FF, Porto-Neto ST, Campos EA. Effect of thermal cycling on fracture toughness of CAD/CAM materials. Am J Dent 2018; 31: 205-210.

[28] Shafter M, Jain V, Wicks R, Nathanson D. Effect of Thermocycling on Flexural Strength of Different CAD/CAM Material. J Dent Oral Disord.2017; 3: 1071.

[29] Morresi AL, D’Amario M, Monaco A, Rengo C, Grassi FR, Capogreco M. Effects of critical thermal cycling on the flexural strength of resin composites. J Oral Sci 2015; 57: 137-143.

[30] Li, Q Yu, H, Wang, Y. Spectrophotometric evaluation of the optical influence of core build-up composites on all-ceramic materials. Dent Mater 2009; 25: 158-165.

[31] Francescantonio, M, Rueggeberg, FA, Arrais, C, Ambrosano G, Giannini, M. biaxial flexure strength and modulus of dual resin cements. Rev Ondonto Cienic 2012; 27: 147-151.

[32] Prakki A, Cilli R, Da Costa AU, Goncalves SE, Mondelli RF, Pereira JC. Effect of resin luting film thickness on fracture resistance of a ceramic cemented to dentin. J Prosthodont 2007; 16: 172-178.

[33] Scherrer SS, de Rijk WG, Belser UC, Meyer JM. Effect of cement film thickness on the fracture resistance of a machinable glassceramic. Dent Mater 1994; 10: 172-177.

[34] Hamed JG, Bakry SI, Hussein SA, Al Abbassy FH. Evaluation of biaxial flexural strength and translucency of multichromatic translucent zirconia and lithium disilicate ceramics. Alex Dent J 2018; 43: 86-93.

[35] Piconi C, Maccauro G. Zirconia as a ceramic biomaterial. Biomaterials 1999; 20: 1-25

[36] Johansson C, Kmet G, Rivera J, Larsson C, Vult Von Steyern P. Fracture strength of monolithic all-ceramic crowns made of high translucent yttrium oxide stabilized zirconium dioxide 
compared to porcelain veneered crowns and lithium disilicate crowns. Acta Odontol Scand 2014; 72: 145-153.

[37] Borba M, Bona AD, Cecchetti D. Flexural strength and hardness of direct and indirect composites. Dent Mater 2009; 23: 5-10.
[38] Cesar PF, Miranda Jr. WG, Braga RR. Influence of shade and storage time on the flexural strength, flexural modulus, and hardness of composites used for indirect restorations. J Prosthet Dent 2001; 86: 289-96. 